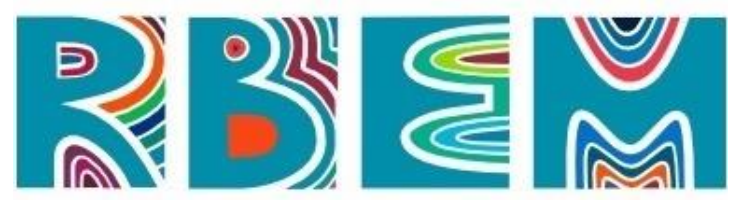

REVISTA BAIANA DE EDUCAÇÃO MATEMÁTICA

ARTIGO

do] https://doi.org/10.47207/rbem.v1i.10321

\title{
Argumentação e Prova em Matemática: uma análise dos itens públicos do PISA 2012
}

\author{
AGUILAR JÚNIOR, Carlos Augusto \\ Universidade Federal Fluminense (UFF). Doutor em Educação pelo Programa de Pós-Graduação em Educação \\ da Universidade do Estado do Rio de Janeiro (ProPEd/UERJ). \\ ORCID: https://orcid.org/0000-0003-0199-0360. E-mail: carlosaugustobolivar@ hotmail.com.
}

\author{
CALDATO, João Carlos \\ Instituto Federal do Rio de Janeiro (IFRJ). Doutorando em Ensino e História da Matemática e da Física pelo \\ Programa de Pós-Graduação em Ensino de Matemática da Universidade Federal do Rio de Janeiro \\ (PEMAT/UFRJ). \\ ORCID: https://orcid.org/0000-0001-6951-3590. E-mail: joao.caldato.correia@gmail.com.
}

\begin{abstract}
Resumo: Neste artigo, o objetivo é analisar os itens públicos do Programa Internacional de Avaliação dos Estudantes (PISA, em inglês) de 2012 que versem sobre argumentação e prova em Matemática. Estes itens exploram os três processos matemáticos (formular, empregar e interpretar), fundamentais para o desenvolvimento da capacidade de raciocinar e argumentar, e definem o letramento matemático segundo a matriz de referência do PISA. Na abordagem teórico-metodológica, recorremos a trabalhos referenciados na literatura que discutem as funções da prova, bem como apresentam outros trabalhos exploratórios envolvendo estudantes e professores. $\mathrm{O}$ estudo se caracteriza por uma pesquisa documental, de cunho qualitativo. No levantamento realizado na base de questões públicas disponível no site do Instituto Nacional de Estudos e Pesquisas Educacionais Anísio Teixeira (INEP), selecionamos 10 itens que atendiam a critérios previamente estabelecidos e procedemos à análise de três destes itens, um de cada processo matemático, à luz dos referenciais que discutem os papéis da prova. Os resultados mostram que os itens buscam mobilizar no estudante habilidades que tencionam o desenvolvimento do raciocínio lógico, conforme estabelecido na BNCC. A título de conclusões parciais, consideramos que a abordagem dessas questões em avaliações de largo alcance, bem como em avaliações institucionais (realizadas pela própria escola), estimula o trabalho pedagógico voltado à construção das habilidades de argumentar e demonstrar, que serão úteis tanto para o desenvolvimento em Matemática como também para sua atuação em um contexto social mais ampliado.
\end{abstract}

Palavras-chave: BNCC. Habilidades e competências. Argumentação e prova matemática. Raciocínio lógico-dedutivo.

\section{Argumentation and Proof in Mathematics: an analysis of public itens from PISA 2012}

\begin{abstract}
This article aims to analyse the public itens of the Programme for International Student Assessment (PISA) of 2012 about argumentation and proof in Mathematics. These itens explore the three mathematical processes (to formulate, to employ and to interpret), basic for the development of the capacity to reason and to argumentate and define mathematical literacy according to PISA reference matrix. In the theoretician-metodological approach, we appeal to papers referrenced in
\end{abstract}




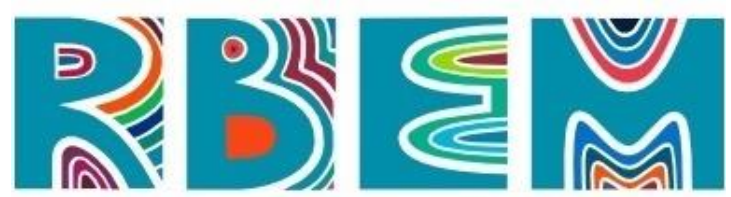

REVISTA BAIANA DE EDUCAÇÃO MATEMÁtICA

literature that discuss the functions of proof, and present other exploratory works involving students and teachers. The study is characterized as a documentary qualitative research. In the survey carried through among the public questions available in the site of the Instituto Nacional de Estudos e Pesquisas Educacionais Anísio Teixeira (INEP), 10 itens have been selected, according to the previously established criteria. Then, three from these itens have been analysed, one of each mathematical process, under the light of the refererred documents that discuss the roles of proof. The results show that the itens look forward to mobilize in the student abilities on the development of the logical reasoning, as established in the BNCC. For the purpose of partial conclusions, we consider that the approach of these questions in large-scale evaluations, as well as in institutional evaluations (carried through by the proper school), stimulates the pedagogical work concerning the construction of the abilities to argumentate and to demonstrate, which will be useful for the development in Mathematics, as well as for the performance in a more extended social context.

Keywords: BNCC. Skills and competencies. Argumentation and mathematical proof. Logicaldeductive reasoning.

\section{Argumentación y Prueba en Matemáticas: un análisis de los ítems públicos de PISA 2012}

Resumen: En este artículo el objetivo es analizar los ítems públicos del Programa Internacional de Evaluación de Alumnos (PISA, en inglés) de 2012 que abordan la argumentación y la prueba en Matemáticas. Estos ítems exploran los tres procesos matemáticos (formular, emplear e interpretar), que son fundamentales para el desarrollo de la capacidad de razonar, argumentar y definir la competencia matemática según la matriz de referencia PISA. En el enfoque teórico-metodológico utilizamos trabajos referenciados en la literatura que discuten las funciones de la prueba, así como presentan otros trabajos exploratorios que involucran a estudiantes y docentes. El estudio se caracteriza por una investigación documental, de carácter cualitativo. En la encuesta realizada a partir de preguntas públicas disponibles en la página web del Instituto Nacional de Estudos e Pesquisas Educacionais Anísio Teixeira (INEP), se seleccionaron 10 ítems que cumplían criterios previamente establecidos y se procedió a analizar tres de estos ítems, uno de cada proceso matemático, a la luz de las referencias que discuten los roles de la prueba. Los resultados muestran que los ítems buscan movilizar en el alumno habilidades que pretendan el desarrollo del razonamiento lógico, conforme lo establecido en el BNCC. Como conclusiones parciales, consideramos que abordar estos temas en evaluaciones de amplio alcance, así como en evaluaciones institucionales (realizadas por la propia escuela), estimula el trabajo pedagógico orientado a construir las habilidades de argumentación y demostración, que serán de utilidad tanto para el desarrollo en Matemáticas, así como para su desempeño en un contexto social más amplio.

Palavras-Clave: BNCC. Habilidades y competencias. Argumentación y prueba matemática. Razonamiento lógico-deductivo.

\section{Introdução}

O que é ensinar matemática? Restringe-se a fazer com que nossos estudantes dominem técnicas de cálculo e resolução de enunciados/problemas? Os Parâmetros Curriculares 


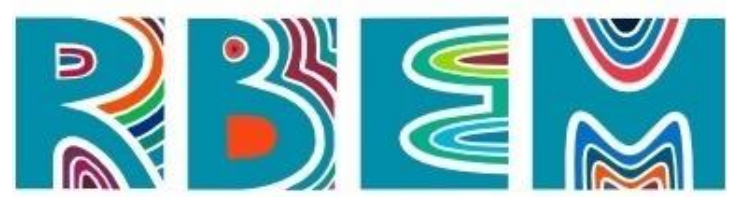

REVISTA BAIANA DE EDUCAÇÃO MATEMÁtICA

Nacionais (PCN) dos anos finais do ensino fundamental e do ensino médio (BRASIL, 1998, 1999) preceituam, para além dessas habilidades, o trabalho com o desenvolvimento do raciocínio lógico-dedutivo por meio de atividades pedagógicas que fomentam a argumentação e prova desde então. Tomando como referência um dos princípios norteadores dos PCN, o ensino de Matemática deveria

[...] garantir o desenvolvimento de capacidades como: observação, estabelecimento de relações, comunicação (diferentes linguagens), argumentação e validação de processos e o estímulo às formas de raciocínio como intuição, indução, dedução, analogia, estimativa (BRASIL, 1998, p. 56).

Muitas são as pesquisas que exploram o trabalho com argumentação e provas na sala de aula do ensino básico (LIMA; SANTOS, 2020; NOTARE; BASSO, 2018; CALDATO; UTSUMI; NASSER, 2017; NUNES; ALMOULOUD, 2013; AGUILAR JÚNIOR; NASSER, 2012). Em comum, essas pesquisas ressaltam a importância de se trabalhar com atividades exploratórias com os estudantes do ensino básico, visando ao fomento da cultura da argumentação em sala de aula (BOAVIDA, 2005) e ao desenvolvimento do raciocínio matemático por meio da construção de argumentos que "demonstrem" a validade de uma afirmação.

Lima e Santos (2020) trazem contribuições de autores consagrados na discussão sobre argumentação e prova no ensino de Matemática. Os autores afirmam que o trabalho pedagógico envolvendo essa temática não pode ser direcionado com o objetivo de que os estudantes demonstrem teoremas como o faz o matemático na Academia. Defendem que os discentes possam ser instigados a explorar mais a compreensão da Matemática por meio da análise dos enunciados dos teoremas para buscar argumentos convincentes que justifiquem a afirmação feita, bem como formular conjecturas ou mesmo refutá-las. Desta forma, as demonstrações de teoremas, propriedades e proposições/corolários em Matemática poderiam fazer sentido para esses estudantes.

O trabalho de Notare e Basso (2018), de caráter qualitativo exploratório, realizado no âmbito de um curso de formação inicial de professores em ambiente virtual, com a exploração de softwares computacionais, destaca a importância do desenvolvimento pedagógico com a prova no sentido de favorecer a compreensão e as conexões entre os diversos conhecimentos matemáticos. Os autores consideram que o ato de demonstrar em Matemática é uma tarefa 


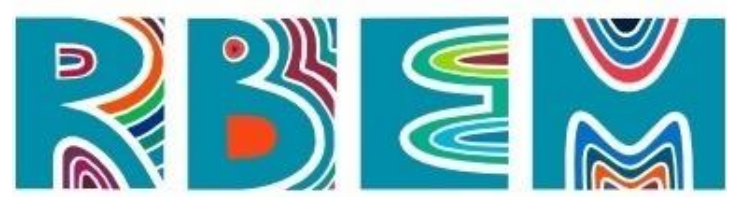

REVISTA BAIANA DE EDUCAÇÃO MATEMÁTICA

natural desta ciência e destacam que não estão "defendendo o trabalho com provas matemáticas que envolvem excesso de rigor e formalismo, mas o processo de raciocínio lógico-dedutivo como ferramenta essencial para a compreensão da Matemática” (p. 1).

Essas reflexões dialogam com a defesa de Aguilar Júnior e Nasser (2012), Nunes e Almouloud (2013) e de Caldato, Utsumi e Nasser (2017), no que dizem respeito ao trabalho com argumentação e prova no ensino básico para o desenvolvimento mais amplo do raciocínio lógico-dedutivo, em diálogo com as preocupações constantes nos textos curriculares orientadores, tais como os PCN, as Diretrizes Curriculares e, mais recentemente, a Base Nacional Comum Curricular (BNCC).

Aguilar Júnior e Nasser (2012) desenvolveram uma pesquisa em duas etapas, sendo uma referente à aplicação e à coleta de respostas a um questionário com questões de raciocínio argumentativo em Matemática e uma segunda, em que professores no ensino básico avaliaram respostas selecionadas, com base nos tipos de prova de Balacheff (1988), de estudantes participantes da primeira fase. Valendo-se também de um estudo exploratório, os autores concluem que os resultados encontrados nas respostas dos estudantes permitem inferir que não há um trabalho pedagógico mais sistematizado com argumentações que levem a uma demonstração por parte dos estudantes da escola básica (p. 145).

Nunes e Almouloud (2013) descrevem em seu manuscrito a metodologia de Toulmin para avaliar os níveis argumentativos apresentados por estudantes referentes ao desenvolvimento das habilidades de provar e demonstrar em Matemática, evidenciando a prática da argumentação como método que favorece a compreensão dos conceitos (p. 488). Nesse estudo, de cunho qualitativo, caracterizado pela metodologia do estudo de caso, os pesquisadores perceberam que o estímulo ao trabalho pedagógico com a argumentação e a prova em sala de aula e no laboratório de Matemática possibilitou que os discentes investigados aprendessem e compreendessem melhor os conceitos de área e perímetro das figuras planas.

Caldato, Utsumi e Nasser (2017), em pesquisa semelhante àquela realizada por Aguilar Júnior e Nasser (2012), aplicaram questionários a alunos do $9^{\circ}$ do ensino fundamental e professores de 2 escolas públicas paulistas, de modo que fosse possível constatar as percepções de estudantes e de professores acerca dos processos de argumentação e prova desenvolvidos (ou não) na escola básica. Em seu estudo, concluem que os professores 


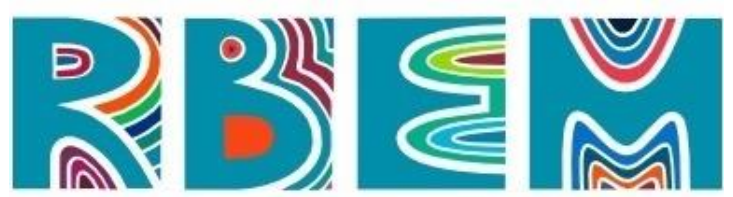

REVISTA BAIANA DE EDUCAÇÃO MATEMÁtICA

participantes, embora tenham declarado que receberam durante seus cursos de formação inicial estímulos para o desenvolvimento de atividades pedagógicas voltadas ao trabalho com argumentação e prova, confundem-se quanto à compreensão das diferenças entre estas terminologias (argumentação, prova e demonstração), indicando não haver um trabalho pedagógico mais sistematizado que desenvolva a habilidade de argumentar e provar resultados em Matemática.

Tais discussões iniciais reforçam sobre nós, pesquisadores e proponentes deste trabalho, a importância do trabalho pedagógico com argumentação, visando ao desenvolvimento do raciocínio lógico-dedutivo, caro ao desenvolvimento em Matemática e ao próprio exercício da cidadania do educando, fomentando a construção da habilidade de justificar e demonstrar. Para tanto, considerando as influências das agendas internacionais, como a da Organização para Cooperação e Desenvolvimento Econômico (OCDE) e do Banco Mundial, como indutoras de reformas curriculares, especialmente por meio da centralização de um modelo curricular que valoriza o trabalho pedagógico pautado pelo desenvolvimento de habilidades e competências, propusemos o presente trabalho com o objetivo de analisar itens do Programme for International Student Assessment (PISA) de 2012, que versem sobre argumentação e prova em Matemática.

É importante destacar que a escolha pelo PISA de 2012 deve-se ao fato de ter sido essa a última edição em que a Matemática fora o foco da avaliação. Isso ocorrerá novamente apenas na edição de 2022. A escolha desta avaliação de largo alcance justifica-se pelo fato de sua matriz de referência (BRASIL, 2013b) apresentar intercruzamentos e aproximações com a Base Nacional Comum Curricular (BRASIL, 2018), que passou a ser referência nacional para construção das matrizes curriculares e de referência das avaliações externas, como é o caso do novo Sistema de Avaliação da Educação Básica (SAEB).

Nosso trabalho é um estudo exploratório, de caráter documental, que analisou as questões públicas do PISA 2012 segundo as funções da prova problematizadas por De Villiers (1990, 1999) e Hanna (1990, 1995), dialogando também com a BNCC, especialmente no contexto das competências matemáticas na educação básica.

Ademais, nosso trabalho aproxima-se da proposta de Ortigão, Santos e Lima (2018) envolvendo questões da prova cognitiva de Matemática da edição do PISA 2012, no que tange à análise das questões em relação ao seu conteúdo. Os pesquisadores, além dessa 


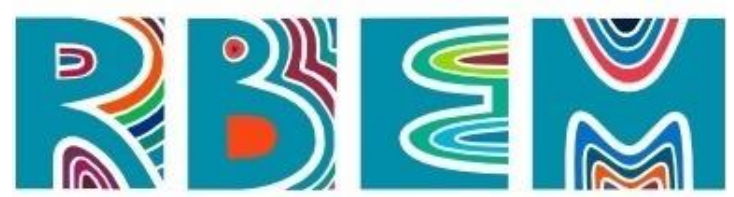

REVISTA BAIANA DE EDUCAÇÃO MATEMÁtICA

análise, realizaram um estudo exploratório com os dados estatísticos dessa edição, bem como aplicaram os itens públicos a estudantes com o perfil da amostra PISA (alunos de 15 anos, matriculados no $1^{\circ}$ ano do ensino médio) de duas escolas públicas estaduais do Rio de Janeiro. À semelhança do que realizaram esses autores, pretendemos, em uma segunda fase desta investigação, aplicar referidas questões a estudantes das redes públicas e privadas, segundo o corte do PISA para seleção da amostra (estudantes entre 15 e 17 anos que estejam cursando a partir do $8^{\circ}$ ano do ensino fundamental).

Além desta seção introdutória, este texto apresenta outras cinco: a segunda seção traz uma breve discussão teórica sobre o significado e as funções da prova em Matemática; a terceira apresenta os aspectos metodológicos, dialogando com os atuais textos curriculares que abordam o trabalho pedagógico com argumentação e prova, no contexto do desenvolvimento do raciocínio lógico-dedutivo; na quarta, apresentamos a noção de letramento matemático segundo a matriz do PISA e os três processos matemáticos (formular, empregar e interpretar), bem como uma breve descrição desta avaliação; na quinta seção, procedemos à análise dos itens públicos do PISA 2012, à luz dos aportes teóricos selecionados; a sexta e última seção traz algumas considerações acerca desta pesquisa; finalizamos o texto com os devidos agradecimentos e as referências utilizadas.

É importante ressaltar que este artigo é uma versão revisada e ampliada do texto originalmente enviado ao IX Seminário de Pesquisa em Educação Matemática (SPEM) do Rio de Janeiro, apresentado no grupo de discussão "Educação Matemática na Educação Básica e Superior” e publicado nos anais do evento (AGUILAR JÚNIOR; CALDATO, 2020).

\section{Fundamentação teórica: o significado e as funções da prova}

Do ponto de vista teórico, utilizamos as discussões trazidas por De Villiers (1990, 1999) e Hanna (1990, 1995). Contudo, antes de apresentar quais são as funções da prova, é importante conceituar qual o significado da palavra "prova" no contexto da argumentação matemática, levando em consideração o nosso local de fala, como professores da educação básica e como educadores matemáticos.

De acordo com Balacheff (1982), um dos pesquisadores mais citados quando se trata desta temática, existem diferenças entre os termos "argumentação", "prova" e 


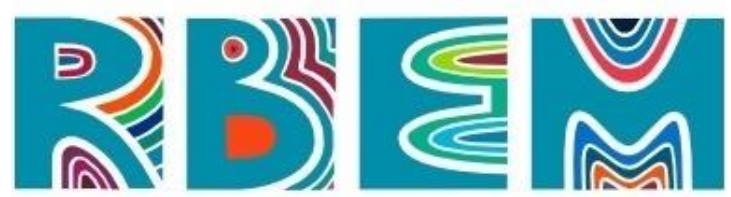

REVISTA BAIANA DE EDUCAÇÃO MATEMÁTICA

"demonstração". O ato de argumentar consiste em um discurso que busca justificar uma afirmação, que poderá ser ou não tomada como verdadeira e aceita pela comunidade epistêmica. A aceitação de tal argumentação converte-a em uma prova no âmbito desta comunidade. Já a demonstração é a prova no contexto acadêmico, sendo aceita pela comunidade dos matemáticos como forma de validar as afirmações.

Vale destacar, como em Almouloud (2007), que as demonstrações

[...] respeitam certas regras: alguns enunciados são considerados verdadeiros (axiomas), outros são deduzidos destes ou de outros anteriormente demonstrados a partir de regras de dedução tomadas num conjunto de regras lógicas e trabalham sobre objetos matemáticos com um estatuto teórico, não pertencentes ao mundo sensível, embora a ele façam referência (ALMOULOUD, 2007, p. 3).

Deste modo, a partir das leituras de Balacheff (1892) e de Almouloud (2007), consideramos que toda demonstração é uma prova, no caso, uma prova matemática, porém nem toda prova é uma demonstração.

Além disso, acreditamos que ensinar por meio de uma prova consiste em mostrar ao educando a validade da declaração feita, exibindo as etapas do processo dedutivo, para assim desenvolver seu raciocínio lógico-dedutivo e com isto possibilitar a construção de habilidades $\frac{7}{\text { D) BWEVIISA }}$ e competências em Matemática. No entanto, é imprescindível que o nível de (in)formalidade e de rigor das provas esteja em consonância com o público a ser atingido, visto que uma argumentação legitimada, por exemplo, pela comunidade estudantil do ensino fundamental, pode não ter a mesma aceitação no ensino médio.

Compreendemos que a apresentação de uma prova não deve ter um fim em si mesma, mas um meio para atingir um fim. Em outras palavras, o uso da prova não deve servir apenas para validar uma afirmação que os alunos já conhecem ou sabem que é verdadeira, pois isso poderia suscitar certo desinteresse por parte deles, mas, se este uso for concebido como um potencial recurso metodológico, conforme defendido por Caldato (2018), isso pode promover a criação de um ambiente favorável à prática da cultura argumentativa.

Neste sentido, De Villiers (1999) afirma que a literatura apresenta uma visão limitada de prova, na qual é definida apenas em termos de sua função de verificação. Em virtude disso, o autor não ignora a importância dessa função, especialmente nos casos em que os resultados não são intuitivos, mas evidencia a necessidade de uma perspectiva mais ampla, 


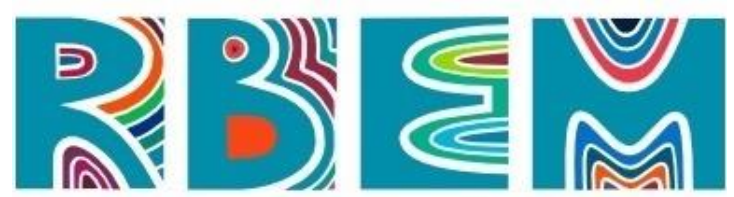

REVISTA BAIANA DE EDUCAÇÃO MATEMÁtICA

especialmente na pesquisa em Educação Matemática, tencionando especialmente seus desdobramentos para o ensino de Matemática.

De acordo com De Villiers (1990, 1999), uma prova pode assumir o papel de:

a) Verificação (validar uma afirmação);

b) Explicação (esclarecer as razões de uma afirmação ser verdadeira);

c) Descoberta (descobrir/inventar novos resultados);

d) Sistematização (organizar os vários resultados em um sistema dedutivo de axiomas, definiç̧ões, proposições e teoremas);

e) Comunicação (transmitir o conhecimento matemático);

f) Desafio intelectual (satisfação pessoal).

Neste artigo, aprofundaremos a nossa reflexão sobre as três primeiras funções, as quais também dialogam com os itens públicos que analisaremos do PISA 2012.

Reid e Knipping (2010) corroboram que a verificação é a função mais assumida no ensino, assim como na visão dos alunos britânicos na pesquisa de Healy e Hoyles (1998), na qual os autores concluíram que cerca de $50 \%$ dos estudantes descrevem a prova como algo que estabelece a verdade de uma afirmação matemática. Entretanto, a prova com esse significado pode até validar uma conjectura, mas nem sempre permite uma explicação satisfatória das razões que implicam sua veracidade. Considere como exemplo as provas por indução ou por redução ao absurdo. Em virtude disso, geralmente quando os resultados são intuitivos e/ou são apoiados por evidências empíricas convincentes, a função da prova não é da verificação, mas sim da explicação.

Contudo, nem sempre o papel da prova é de verificação ou explicação. Apesar de parecer contraditório, em geral, os resultados matemáticos são descobertos por métodos intuitivos e/ou quase empíricos, antes da produção de uma demonstração. Contudo, a História da Matemática descreve alguns fatos que foram descobertos ou inventados de modo dedutivo como, por exemplo, as geometrias não-euclidianas. Logo, a função da prova muitas vezes consiste em um meio de descoberta para novos resultados (DE VILLIERS, 1999, p. 7-8).

Ao evidenciar algumas das funções das provas descritas por De Villiers (1990, 1999), em particular, de verificação e de explicação, é possível tecer uma analogia com a distinção proposta por Hanna (1990) entre "provas que provam" e "provas que explicam". Segundo a pesquisadora, enquanto as provas que se enquadram no primeiro tipo apenas mostram que o 


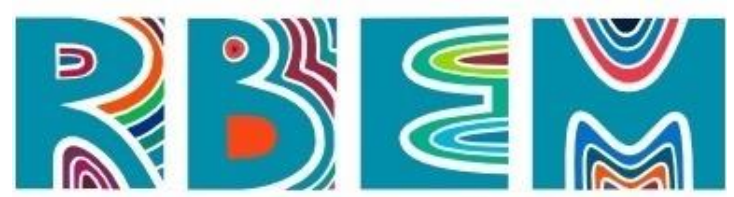

REVISTA BAIANA DE EDUCAÇÃO MATEMÁtICA

resultado é verdadeiro, as do segundo não apenas mostram, como também fornecem uma lógica baseada nas propriedades matemáticas que justificam as razões de ser verdadeiro.

A fim de exemplificar essa diferença, justificamos a seguinte afirmação de duas maneiras distintas: a soma dos $n$ primeiros números naturais ímpares é dada por $S_{n}=n^{2}$.

\section{Justificativa 1:}

Para $n=1$, o resultado é verdadeiro, pois $S(n)=1=1^{2}$.

Assim, assumindo que a propriedade é válida para $k$ arbitrário, ou seja, $S(k)=1+3+5+$ $\cdots+2 k-1=k^{2}$, é possível mostrar que continua valendo para $n=k+1$. De fato, pois $S(k+1)=(1+3+5+\cdots+2 k-1)+(2 k+1)=k^{2}+2 k+1=(k+1)^{2}$.

Portanto, a afirmação é verdadeira para $k+1$ se é verdade para $k$. Por indução finita, a propriedade é válida para todo o $n \in N$.

Justificativa 2:

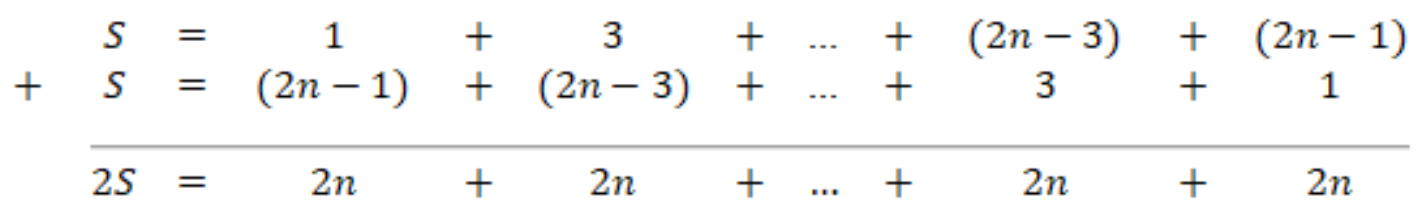

É possível observar que em $S(n)$ há $n$ parcelas de $2 n$, o que implica que $2 S=n(2 n)$. Logo, a soma dos $n$ primeiros ímpares é dada por $S_{n}=n^{2}$, para todo o $n \in N$.

Note que na primeira justificativa a fórmula foi demonstrada por indução. No entanto, esse argumento não evidencia quais são os reais motivos que justificam a fórmula $S_{n}=n^{2}$ ser verdadeira e, por isso, a referência a provas que apenas provam. Já na segunda, ao recorrer à noção de simetria, que é fundamental para a demonstração, torna-se compreensível o porquê de a fórmula ser dada por $n^{2}$ e por isso a referência a provas que explicam. É importante destacar que, segundo Hanna (1990, p. 9), visão com a qual concordamos, ambas as justificativas são legítimas do ponto de vista matemático, pois cumprem o propósito de garantir a validade da afirmação.

Contudo, Gila Hanna defende que na Matemática escolar a principal função da prova é de explicação, enquanto na Matemática acadêmica seria de verificação. "Por esta razão, a prova não deve ser realizada em sala de aula como um ritual, visando vagamente refletir a prática matemática, mas sim como uma atividade instrutiva e significativa" (HANNA, 1995, p. 47, tradução nossa).

Retomando o seu artigo de 1990, Hanna também discute o Movimento da Matemática 


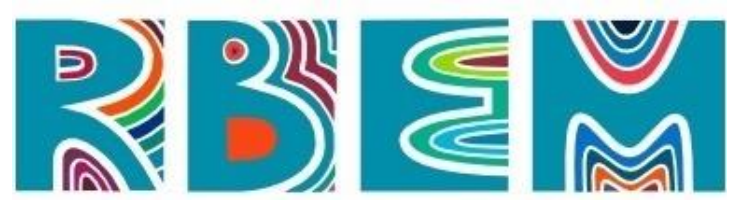

REVISTA BAIANA DE EDUCAÇÃO MATEMÁTICA

Moderna, que é uma reavaliação quanto ao papel das estruturas axiomáticas e das provas formais - constituídas por uma sequência finita de sentenças, cuja primeira é um axioma, as seguintes são outros axiomas ou consequências lógicas dedutivas e a última é a que deve ser provada -, que se assemelha à noção de demonstração proposta por Balacheff (1982). Segundo a autora,

[...] neste novo olhar, as provas passam a ter diferentes graus de validade formal, mantendo o mesmo grau de aceitação, permitindo com isso a reconsideração do que poderia ser prova ideal e de que se deveria ensinar nas escolas (HANNA, 1990, p. 8, tradução nossa).

A pesquisadora refere-se a esta nova percepção como "prova aceitável", na qual o nível de exigência do argumento dado para se comprovar uma declaração matemática não precisa necessariamente seguir os padrões de rigidez quanto à validade de proposições, teoremas e corolários. Desse modo, percebe-se que muitos educadores matemáticos assumem uma postura de afastamento quanto à exigência ou dependência extrema de provas rigorosas em Matemática, dando ênfase na concepção de prova como argumento convincente, conforme é possível observar na conceituação de prova proposta por Balacheff (1982), por exemplo.

Essas discussões teóricas são importantes para fundamentar as análises que faremos das questões do banco de itens públicos do PISA 2012, e também nos possibilitam pensar os procedimentos metodológicos que adotamos para conduzir nossa pesquisa. A seção seguinte dedica-se à apresentação e discussão sobre os procedimentos metodológicos.

\section{Procedimentos metodológicos}

Nosso estudo define-se como uma pesquisa documental, visto que as principais referências foram fontes primárias caracterizadas "pela relação direta com os fatos a serem analisados" (GONSALVES, 2001, p. 32). No caso, utilizamos os seguintes documentos oficiais referentes ao PISA 2012: os itens liberados de Matemática, o relatório nacional e a matriz de avaliação de Matemática (BRASIL, 2012, 2013a, 2013b). Além disso, também analisamos a BNCC.

Durante a leitura deste último documento, buscamos identificar trechos que discutiam conceitos, ideias e preceitos referentes às habilidades e competências relacionadas à 


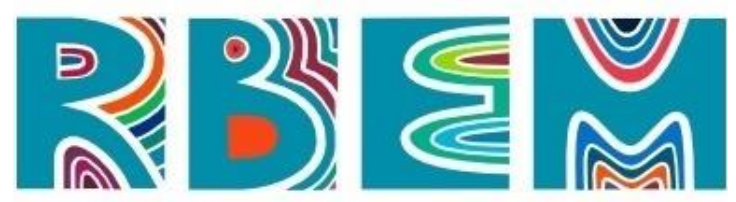

REVISTA BAIANA DE EDUCAÇĀO MATEMÁTICA

argumentação e prova. Para tanto, realizamos buscas por meio de alguns prefixos, como “argument”, “justi”, “expli”, “demonstr”, "prov”, “mostr” e "raciocin”, os quais faziam alusão às palavras argumente, justifique, explique, demonstre, prove, mostre, raciocínio e seus respectivos cognatos. É importante destacar que a triagem dos itens públicos do PISA 2012 também ocorreu por meio da busca por elementos lexicais, como veremos adiante.

Além de habilidades específicas que exploram demonstração, a BNCC apresenta orientações gerais para o trabalho com argumentação e provas, como o trecho a seguir:

Apesar de a Matemática ser, por excelência, uma ciência hipotético-dedutiva, porque suas demonstrações se apoiam sobre um sistema de axiomas e postulados, é de fundamental importância também considerar o papel heurístico das experimentações na aprendizagem da Matemática (BRASIL, 2018, p. 265).

No mesmo texto da BNCC são trazidas competências específicas para o ensino fundamental e o médio. De acordo com o texto, são competências previstas no texto de centralidade curricular, em relação ao ensino fundamental:

2. Desenvolver o raciocínio lógico, o espírito de investigação e a capacidade de produzir argumentos convincentes, recorrendo aos conhecimentos matemáticos para compreender e atuar no mundo.

(...)

4. Fazer observações sistemáticas de aspectos quantitativos e qualitativos presentes nas práticas sociais e culturais, de modo a investigar, organizar, representar e comunicar informações relevantes, para interpretá-las e avaliá-las crítica e eticamente, produzindo argumentos convincentes (BRASIL, 2018, p. 267).

Quanto ao ensino médio, é prevista a seguinte competência:

3. Utilizar estratégias, conceitos, definições e procedimentos matemáticos para interpretar, construir modelos e resolver problemas em diversos contextos, analisando a plausibilidade dos resultados e a adequação das soluções propostas, de modo a construir argumentação consistente (BRASIL, 2018, p. 531).

Considerando essas competências, vimos que guardam relação com as funções da prova no processo de ensino-aprendizagem em Matemática, nos termos colocados por De Villiers (1990, 1999). Dessa forma, todo este arcabouço teórico permitirá que nossa análise consiga identificar essas funções nos itens públicos selecionados do PISA 2012, em um diálogo com as competências propostas na BNCC. 


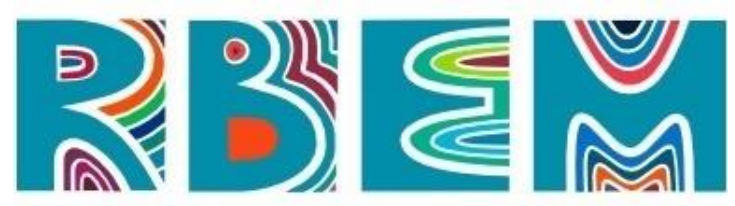

REVISTA BAIANA DE EDUCAÇÃO MATEMÁTICA

Tal articulação com a BNCC deve-se ao fato de que este documento curricular foi pensado em meio às tensões advindas dos resultados brasileiros nas avaliações internacionais de largo alcance, bem como pela posição do Brasil na agência internacional e pelas políticas emanadas pelas agências multilaterais, destacadamente a OCDE e o Banco Mundial, como se pode verificar na discussão realizada por Jolandek (2020). De forma resumida, essas agências defendem que os currículos abordem a construção de habilidades e competências em detrimento de um trabalho mais sistematizado com as disciplinas escolares. O PISA é organizado e aplicado em cooperação com os países-membros e "convidados" pela OCDE.

Na próxima seção, discutiremos o significado de letramento matemático e os três processos matemáticos definidos pelo PISA.

\section{PISA: letramento matemático e os processos de formular, empregar e interpretar}

Como comentado na parte introdutória, a proposta de trabalho com a exploração dos itens do PISA 2012 foi inspirada no trabalho desenvolvido por Ortigão, Santos e Lima (2018). Os autores selecionaram itens públicos deste exame internacional que envolviam os subtemas de Geometria e aplicaram a estudantes com o perfil semelhante ao do público-alvo do PISA. Inspirados na proposta, realizamos uma seleção dentre os itens públicos que abordassem o desenvolvimento das habilidades relacionadas ao raciocínio matemático por meio da argumentação e da prova matemática. Neste manuscrito, restringimo-nos a discutir estes itens, sem aplicá-los a estudantes, o que será nossa próxima fase de investigação.

Entretanto, antes da discussão dos itens públicos, convém uma apresentação sobre o PISA e o processo de avaliação do letramento matemático que ele pretende realizar. $\mathrm{O}$ Programa Internacional de Avaliação dos Estudantes (PISA, na sigla em inglês), conduzido pela OCDE, tem regularidade trienal e em cada edição avaliam o letramento nas áreas de Leitura, Matemática e Ciências. A nossa escolha pelos itens públicos de 2012 deve-se ao fato de ter sido a última vez que a Matemática foi o foco da avaliação. Na ocasião, o letramento matemático foi definido como sendo

[...] a capacidade individual de formular, empregar e interpretar a matemática em uma variedade de contextos. Isso inclui raciocinar matematicamente e utilizar conceitos, procedimentos, fatos e ferramentas matemáticas para descrever, explicar e 


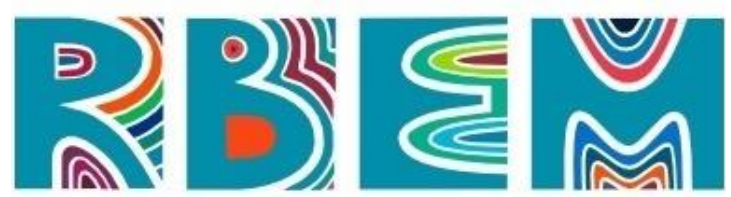

REVISTA BAIANA DE EDUCAÇÃO MATEMÁtICA

predizer fenômenos. Isso auxilia os indivíduos a reconhecer o papel que a matemática exerce no mundo e para que cidadãos construtivos, engajados e reflexivos possam fazer julgamentos bem fundamentados e tomar as decisões necessárias (BRASIL, 2018, p. 266). ${ }^{1}$

Desta definição, depreende-se que o estudante letrado em Matemática é aquele que detém, dentre outras habilidades, aquelas relacionadas ao raciocínio, o que estaria relacionado com a capacidade de elaborar argumentos convincentes que possam justificar a validade (ou não) de afirmações, o que passa pelos processos matemáticos intitulados formular (situações com base na matemática), empregar (conceitos, fatos, procedimentos e raciocínio matemático) e interpretar (resultados matemáticos), estabelecidos como:

Formular: refere-se à capacidade do indivíduo de reconhecer e identificar oportunidades para utilizar a matemática, providenciando uma estrutura matemática para a resolução de um problema apresentado dentro de um contexto.

Empregar: refere-se à capacidade do indivíduo para aplicar conceitos, fatos, procedimento e raciocínio matemáticos para resolver problemas formulados matematicamente e chegar a conclusões.

Interpretar: refere-se à capacidade do indivíduo para refletir sobre soluções, resultados, conclusões e interpretações matemáticas em problemas presentes em um contexto real (BRASIL, 2013a, p. 25, 27, 29).

De acordo com o relatório nacional do PISA 2012, para que um estudante seja letrado em Matemática, são necessárias capacidades fundamentais nessa área, as quais não são medidas diretamente na avaliação, mas estão presentes nos três aspectos relacionados em cada item, sendo eles:

- Processos matemáticos: formular, empregar, interpretar;

- Conteúdo: mudanças e relações, espaço e forma, quantidade, indeterminação e dados;

- Contexto: pessoal, ocupacional, social, científico.

À medida que um estudante aumenta seu nível de letramento em Matemática, ele é capaz de desenvolver cada vez mais as capacidades fundamentais nessa área, e, dentre as sete capacidades mencionadas no relatório nacional e na matriz do PISA 2012, trazemos a conceituação de uma que dialoga diretamente com este artigo,

${ }^{1}$ Esta definição da matriz do PISA 2012 (BRASIL, 2013b) é descrita em nota de rodapé na BNCC. 


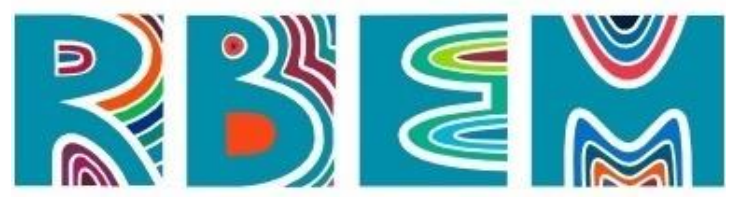

REVISTA BAIANA DE EDUCAÇÃO MATEMÁTICA

[...] conhecida como raciocínio e argumentação. Essa capacidade envolve processos de pensamento logicamente enraizados, que exploram e vinculam elementos de problemas, de modo a fazer inferências a partir deles, verificar uma justificativa dada, ou fornecer uma justificativa sobre uma afirmação ou sobre soluções para problemas (BRASIL, 2013a, p. 25, grifo nosso).

Em virtude disso, é possível afirmar que a capacidade de raciocínio e argumentação permeia os três processos matemáticos. Entretanto, com base em nossa visão crítica a partir das leituras dos documentos oficiais, dentre a descrição de cada um dos processos e as atividades relacionadas, o "empregar" foi o que apresentou maior correlação com esta capacidade fundamental. Para corroborar a nossa afirmação, descrevemos no quadro 1 alguns fragmentos retirados do relatório nacional do PISA 2012:

Quadro 1: Atividades dos processos matemáticos relacionadas com a capacidade de raciocínio e argumentação

\begin{tabular}{|c|c|}
\hline $\begin{array}{l}\text { Processos } \\
\text { matemáticos }\end{array}$ & $\begin{array}{l}\text { Atividades relacionadas } \\
\text { (com a capacidade de raciocínio e argumentação, segundo anossa visão) }\end{array}$ \\
\hline Formular & $\begin{array}{l}\text { "compreender e explicar as relações entre o contexto específico da linguagem de } \\
\text { um problema e a linguagem simbólica e formal necessária para sua representação } \\
\text { matemática" } \\
\text { (p. } 25 \text {, grifo nosso) }\end{array}$ \\
\hline Empregar & $\begin{array}{l}\text { "refletir sobre argumentos matemáticos, explicar e justificar resultados } \\
\text { matemáticos" } \\
\text { "realizar generalizações baseadas nos resultados de aplicação de procedimentos } \\
\text { matemáticos para encontrar soluções" } \\
\text { (p. 27, grifo nosso) }\end{array}$ \\
\hline Interpretar & $\begin{array}{l}\text { "explicar por que um resultado matemático faz ou não sentido dentro do contexto } \\
\text { de um problema" } \\
\text { (p. 29, grifo nosso) }\end{array}$ \\
\hline
\end{tabular}

Fonte: Brasil (2013a).

Para concluir esta seção, trazemos uma observação sobre o processo empregar, que foi constatado no documento sobre os itens liberados pelo PISA 2012. Ao traduzir a expressão original employ do inglês para o português, verificamos que ora ela é traduzida como empregar, ora como aplicar. Contudo, neste artigo, restringimo-nos à primeira tradução.

Após toda a discussão sobre o PISA, na próxima seção faremos a descrição e a análise dos três itens selecionados. 


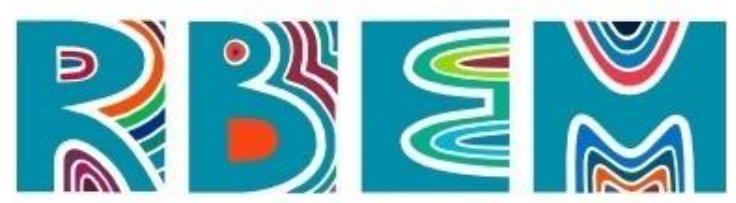

REVISTA BAIANA DE EDUCAÇÃO MATEMÁTICA

\section{Descrição e análise dos itens selecionados}

Com relação aos itens de Matemática da edição do PISA 2012 liberados, disponíveis no site do Instituto Nacional de Estudos e Pesquisas Educacionais Anísio Teixeira (INEP), observaram-se 23 situações-problema, as quais geraram um total de 56 itens/questões, sendo 30 abertos (discursivo ou preenchimento de lacuna) e 26 fechados (múltipla escolha, sim/não ou verdadeiro/falso). Dentre eles, identificamos que em 10 itens abertos discursivos, de 8 situações distintas, solicitou-se, direta ou indiretamente, que os respondentes justificassem as suas respostas.

Essa identificação foi realizada de forma semelhante àquela ocorrida durante a leitura da BNCC, a partir da busca por prefixos relacionados à argumentação e à prova em Matemática.

Observamos que entre os 10 itens identificados havia pelo menos uma questão para cada um dos três processos matemáticos. Isso ratifica o fato de que a capacidade fundamental "raciocínio e argumentação" abrange todos os processos. Sendo assim, a distribuição dos itens foi a seguinte: formular (1), empregar (6) e interpretar (3). Destaca-se o predomínio do processo "empregar" nas questões do PISA 2012 que estimulavam o raciocínio $\frac{15}{\text { D. BW BEVISTA }}$ argumentativo, o que também corrobora com a nossa visão crítica mencionada na seção anterior.

Em vista disso, a partir dos 10 itens que se encaixaram nos critérios adotados, escolhemos três questões para discussão e análise, as quais se enquadram, respectivamente, nos processos de formular, empregar e interpretar.

A situação-problema da figura 1 faz menção à alocação de DVDs, que se desdobra em dois itens. A nossa escolha foi pela questão 2, que abrange o processo de formular, o conteúdo de quantidade e o contexto pessoal. 


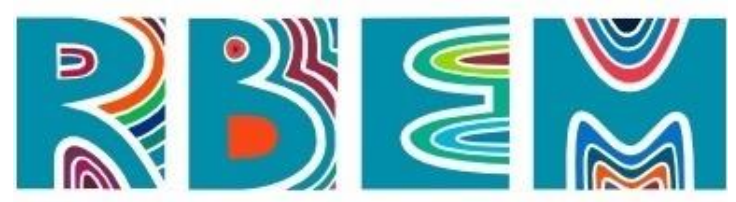

REVISTA BAIANA DE EDUCAÇÃo MATEMÁTICA

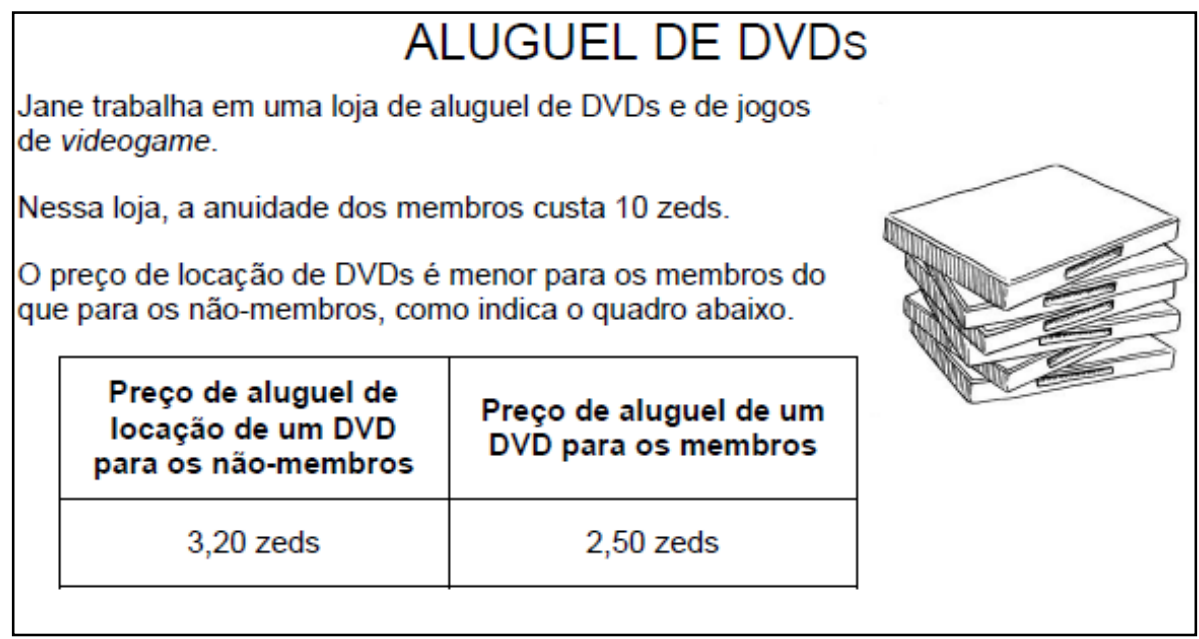

Figura 1: Situação-problema “Aluguel de DVDs” (BRASIL, 2012, p. 56).

O enunciado da questão que suscita o processo formular é o seguinte: "Qual é o número mínimo de DVDs que um membro deve alugar para cobrir os custos da anuidade? Demonstre seu raciocínio."

$\mathrm{O}$ enunciado mobiliza o estudante a construir argumentos convincentes que permitam verificar quantos DVDs devem ser alugados por um membro da loja de modo que o custo da anuidade possa ser coberto. Tal capacidade individual é preceituada como uma daquelas que

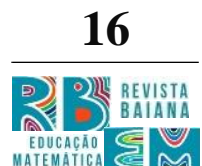
fundamentam o letramento matemático definido na matriz do PISA 2012 e que dialogam com as competências e habilidades estampadas na BNCC, conforme depreende-se da leitura das competências específicas 2 e 4 do ensino fundamental para a Matemática, que foram mencionadas nos procedimentos metodológicos.

Verificamos que esse item estimula o raciocínio lógico-dedutivo do estudante, que formulará argumentos matemáticos e/ou cálculos para mostrar o número mínimo solicitado no comando da questão. Com base em De Villiers (1990, 1999), entendemos que a questão é um tipo de prova que apresenta características da função descoberta, uma vez que o estudante é mobilizado a construir criativamente ou "inventar" argumentos matematicamente corretos que atendam ao comando da questão.

Neste sentido, observamos no banco de itens que as codificações para corrigir essa questão apontam algumas possibilidades de descobertas, conforme ilustra a figura 2: 


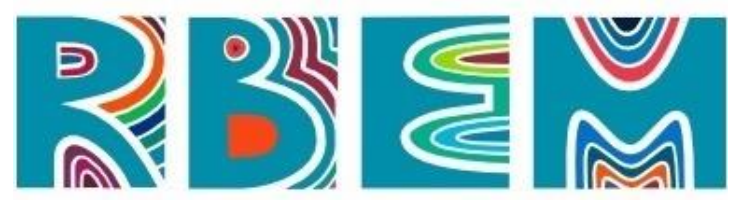

REVISTA BAIANA dE EDUCAÇÃo MATEMÁtICA

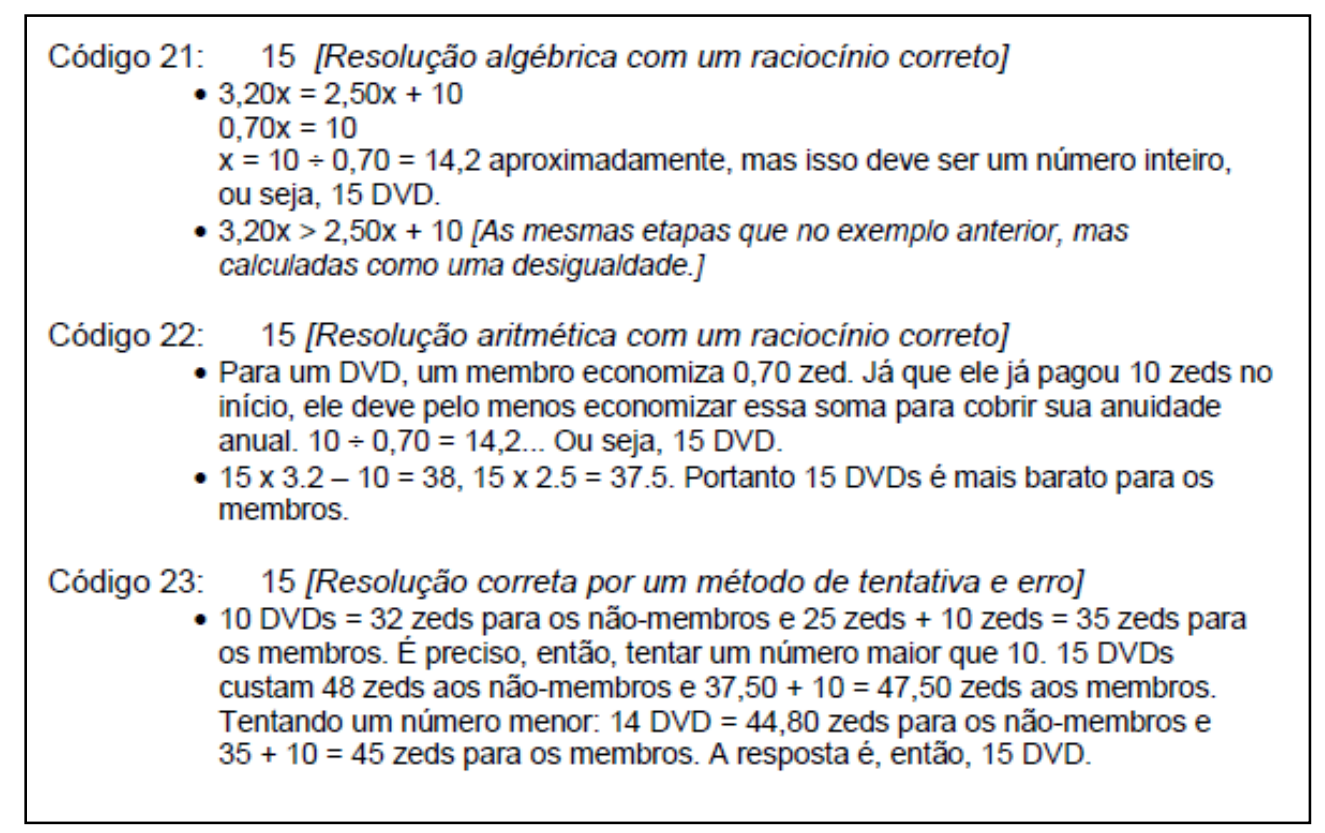

Figura 2: Códigos de correção da questão 2 da situação-problema “Aluguel de DVDs” (BRASIL, 2012, p. 57).

$\mathrm{Na}$ figura 2, vimos alguns códigos de correção para a questão analisada. Todos esses paradigmas de correção conferem à questão o código/a pontuação máxima, uma vez que considera diversas possibilidades de invenção (invenção com o sentido de criação) de respostas matematicamente corretas, a fim de demonstrar a quantidade de DVDs a serem alugados para cobrir o custo com a anuidade: a criação passa por respostas que se pautam em generalidades algébricas e por regularidades aritméticas, bem como tentativa e erro.

A próxima questão escolhida é baseada na situação-problema ilustrada na figura 3 , que aborda a reforma de uma sorveteria e que envolve o processo empregar, o conteúdo de espaço e forma, e o contexto profissional. 


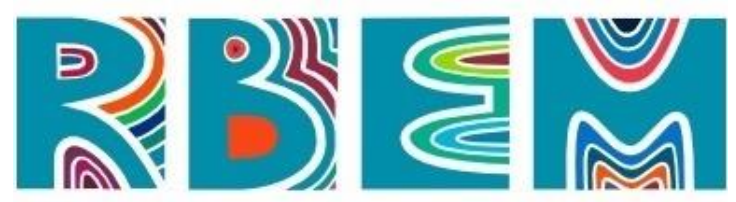

REVISTA BAIANA dE EDUCAÇÃO MATEMÁTICA

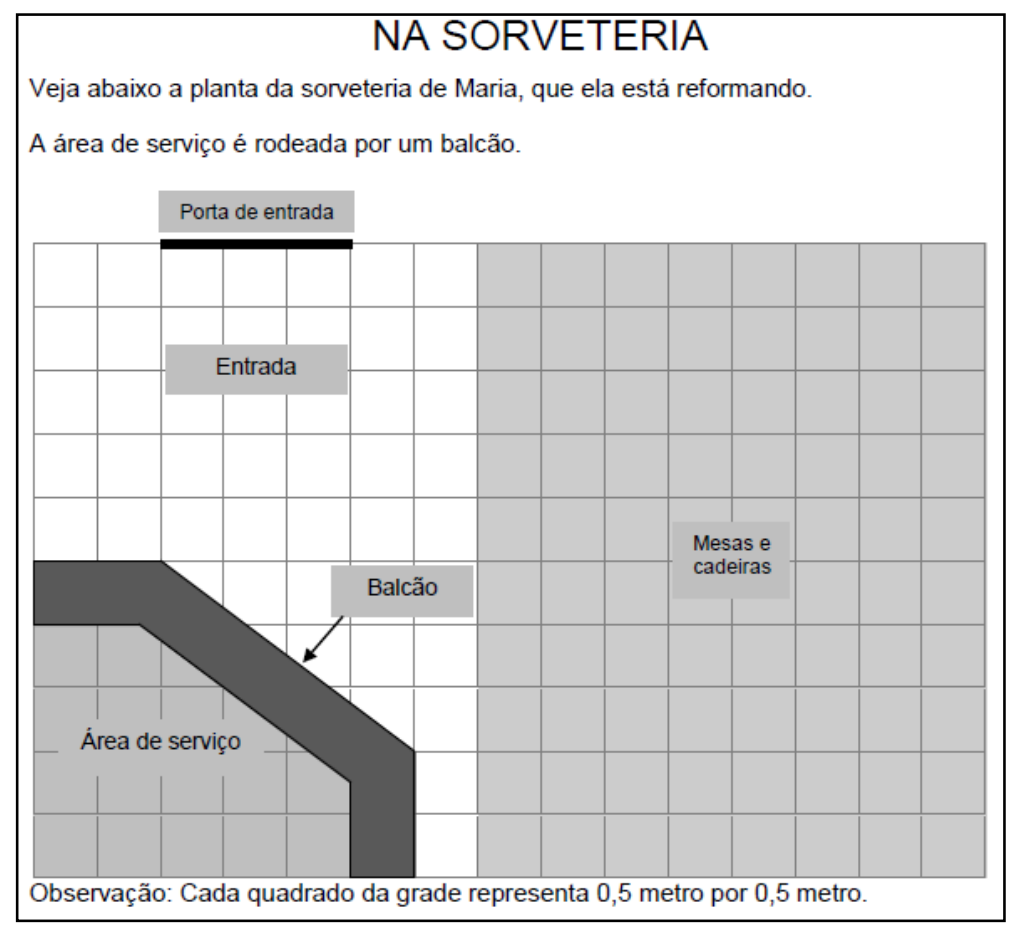

Figura 3: Situação-problema "Na sorveteria” (BRASIL, 2012, p. 12).

Esta situação-problema se desdobrava em três itens, e a nossa escolha foi pela questão 1, cujo comando é o seguinte: "Maria deseja instalar uma nova borda ao longo da parede D) BEVISTA externa do balcão. Qual é o comprimento total da borda de que ela precisa? Demonstre seu raciocínio."

Esta questão exigia que o aluno soubesse interpretar a planta da sorveteria e a escala indicada, na qual cada quadrado da grade representava $0,25 \mathrm{~m}^{2}$. Posteriormente, para calcular o comprimento total da parede externa do balcão, era necessária a aplicação do teorema de Pitágoras. Nesta parte da resolução, o estudante que identificasse a terna pitagórica 3, 4, 5 (cada unidade representaria $0,5 \mathrm{~m}$ ), executaria cálculos mais simplificados. Deste modo, o comprimento solicitado seria dado pela hipotenusa do triângulo pitagórico $(2,5 \mathrm{~m})$ acrescido por quatro unidades $(0,5 \mathrm{~m}$ cada), resultando na resposta $4,5 \mathrm{~m}$. Porém, de acordo com as codificações para corrigir esta questão, o participante atingiria a pontuação máxima se respondesse um valor pertencente ao intervalo de $4,45 \mathrm{~m}$ a $4,55 \mathrm{~m}$, conforme ilustra a figura 4 :

Código 2: Resposta no intervalo de 4,45 a 4,55 [em metros] ou de 445 a 455 [em $\mathrm{cm}$ ] com ou sem demonstração de cálculo.[a faixa pode permitir erro de medida de $\pm 1 \mathrm{~mm}$. Unidades não são requeridas] 


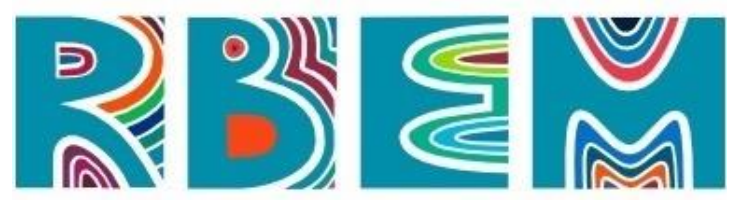

REVISTA BAIANA DE EDUCAÇÃO MATEMÁtICA

Figura 4: Códigos de correção da questão 1 da situação-problema "Na sorveteria" (BRASIL, 2012, p. 13).

Observemos que o estudante, para responder corretamente à questão, precisou empregar conceitos e procedimentos recorrentes em Geometria para obter conclusões, viabilizando a "demonstração" do seu raciocínio. Este tipo de questão dialoga com as discussões realizadas por Hanna (1990), uma vez que estimula a construção de uma argumentação que justifica as escolhas, sem o rigor de uma demonstração. Além disso, apresenta-se como um tipo de prova com as características de verificação e de explicação (DE VILLIERS, 1990, 1999). Particularmente, este item explora a habilidade de utilização de estratégias (leitura de escala), bem como de conceitos matemáticos (unidades de medida, teorema de Pitágoras), para analisar os resultados e construir argumentos consistentes (BRASIL, 2018, p. 531).

A seguir, apresentamos a última questão escolhida que compreende o processo interpretar, o conteúdo de incerteza e dados, e o contexto social.

\begin{tabular}{|c|c|c|c|}
\hline \multicolumn{4}{|c|}{ TV A CABO } \\
\hline \multirow{2}{*}{\multicolumn{4}{|c|}{$\begin{array}{l}\text { A tabela abaixo apresenta dados sobre o número de lares } \\
\text { equipados com aparelhos de televisão (TV) em cinco } \\
\text { paises. } \\
\text { A tabela indica igualmente a porcentagem de lares } \\
\text { equipados com aparelhos de TV e que também são } \\
\text { assinantes de TV a cabo. }\end{array}$}} \\
\hline & & & \\
\hline Pais & $\begin{array}{l}\text { Número de lares } \\
\text { equipados com TV }\end{array}$ & $\begin{array}{l}\text { Porcentagem de lares } \\
\text { equipados com TV } \\
\text { dentre todos os lares }\end{array}$ & $\begin{array}{l}\text { Porcentagem de lares } \\
\text { assinantes de televisão a } \\
\text { cabo dentre os lares } \\
\text { equipados com TV }\end{array}$ \\
\hline Japão & 48,0 milhões & $99,8 \%$ & $51,4 \%$ \\
\hline França & 24,5 milhões & $97,0 \%$ & $15,4 \%$ \\
\hline Bélgica & 4,4 milhões & $99,0 \%$ & $91,7 \%$ \\
\hline Suiça & 2,8 milhões & $85,8 \%$ & $98,0 \%$ \\
\hline Noruega & 2,0 milhões & $97,2 \%$ & $42,7 \%$ \\
\hline
\end{tabular}

Figura 5: Situação-problema “TV a Cabo" (BRASIL, 2012, p. 59). 


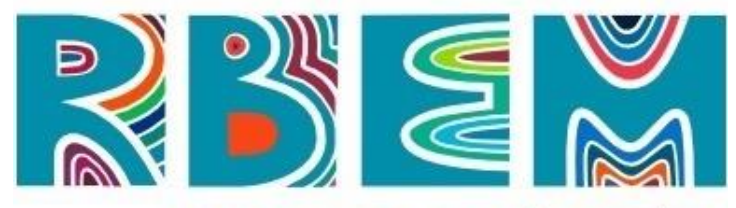

REVISTA BAIANA DE EDUCAÇÃO MATEMÁtICA

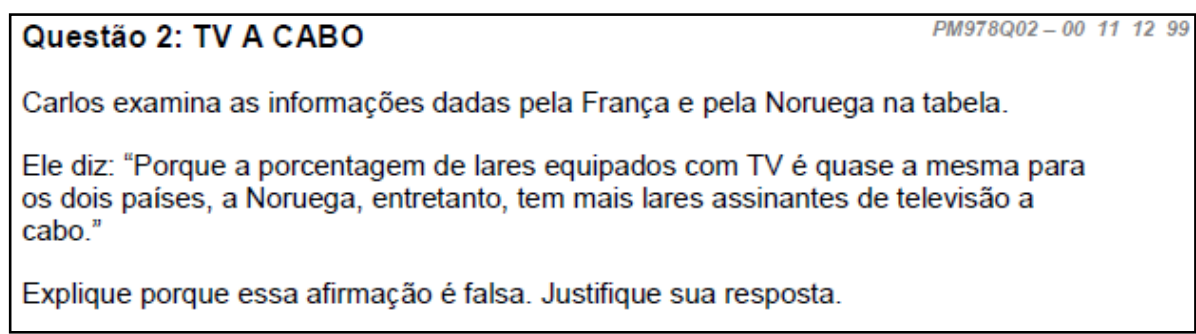

Figura 6: Questão 2 da situação-problema “TV a Cabo” (BRASIL, 2012, p. 60).

As figuras 5 e 6 apresentam, respectivamente, a situação-problema "TV a Cabo", que traz dados tabelados referentes à presença de aparelhos de televisão e de pacote de TV por assinatura nos lares de 5 países (4 europeus e 1 asiático) e a questão que queremos analisar. Essa situação-problema se desdobrava em dois itens e escolhemos a questão 2.

$\mathrm{Na}$ descrição da questão, há a informação de se tratar de um item que explora o processo interpretar. Analisando-a, verifica-se que, de fato, a afirmação é falsa, uma vez que 42,7\% dos 2 milhões de lares noruegueses equipados com televisão (ou seja, 854.000 lares com TV a cabo) não é maior que $15,4 \%$ dos 24,5 milhões de lares franceses que possuem este equipamento (ou 3.773.000 de lares franceses com TV a cabo). Destacamos que a leitura descuidada da tabela pode levar à compreensão de que, realmente, é falsa a afirmativa partindo de uma premissa equivocada: calcular porcentagem de porcentagem. Realmente, ao se calcular $42,7 \%$ de $97,2 \%$ dos 2 milhões de lares noruegueses equipados com televisão, verifica-se que este valor não é maior que $15,4 \%$ de $97 \%$ dos 24 milhões de lares franceses que possuem este equipamento.

Esta mobilização do processo interpretativo nos leva a considerar que o item explora a função da prova assumindo o papel de verificação e de explicação (DE VILLIERS, 1990, 1999), bem como dialoga com a competência 2 do ensino fundamental referente ao desenvolvimento do raciocínio lógico em Matemática, conforme se depreende da leitura da BNCC (BRASIL, 2018, p. 267). A construção da justificativa da afirmação falsa feita pela personagem do enunciado assemelha-se àquele da apresentação de um contraexemplo para demonstrar que a afirmação realizada não é verdadeira.

Feitas as descrições e análises dos três itens que trabalharam com os processos de formular, empregar e interpretar, apontando como esses itens podem ser considerados à luz das funções de prova propostas por De Villiers $(1990,1999)$, passaremos à última seção do 


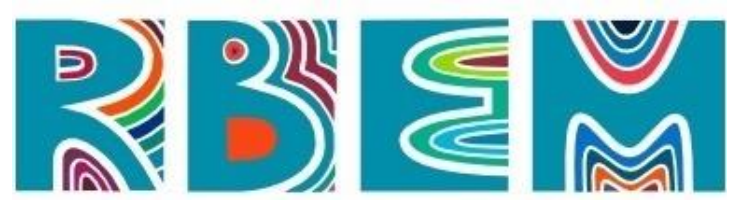

texto, com as considerações finais.

\section{Considerações Finais}

O presente manuscrito é parte inicial de uma pesquisa sobre argumentação e prova no ensino básico que articula a avaliação em largo alcance, como o PISA, com a BNCC. Como discutimos ao longo do texto, é possível inferir que a política de avaliação que perpassa o PISA seja responsável por estampar habilidades e competências que exploram o desenvolvimento do raciocínio lógico-dedutivo em Matemática desde o ensino básico ensino fundamental e médio -, a despeito do que já se propunha nos PCN.

Independentemente das questões relacionadas às avaliações de largo alcance e o que representa social, econômica, cultural e politicamente uma centralização curricular tencionada por organismos internacionais como OCDE e Banco Mundial, vimos de forma positiva que a habilidade de argumentar e demonstrar em Matemática tenha sido contemplada como uma competência a ser desenvolvida no ensino básico.

As questões selecionadas para discussão evidenciam potenciais significativos com o trabalho pedagógico envolvendo argumentação em Matemática, especialmente quando esta habilidade é mobilizada para resolver problemas que extrapolam contextos meramente matemáticos, situações envolvendo realidades sociais plausíveis. São itens que iremos utilizar na próxima fase de nossa investigação, que irá verificar o nível de argumentação e prova matemática dos estudantes com perfil similar ao do público-alvo do PISA.

Um trabalho mais focado em justificativas deve ser estimulado também nos instrumentos de avaliações institucionais (provas, testes, trabalhos internos das escolas, elaboradas pelos professores), conforme nos apontam os trabalhos discutidos na parte introdutória deste texto. Tal movimentação não visa à preparação para os exames externos, mas para a produção de uma cultura da argumentação que é importante para a atuação do estudante em outros contextos sociais, para além da sala de aula de Matemática.

\section{Agradecimentos}

Os autores manifestam os sinceros agradecimentos à Coordenação de 


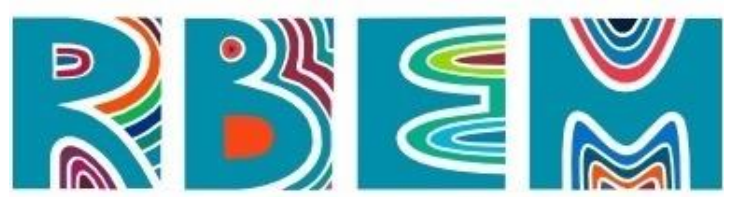

REVISTA BAIANA DE EDUCAÇÃO MATEMÁtICA

Aperfeiçoamento de Pessoal de Nível Superior (CAPES) pelo fomento e incentivo a esta pesquisa. Agradecemos, ainda, às professoras Flávia Trópia, Karen Coutinho Campos Furtado e Maria Helena Monteiro Mendes Baccar, pelo olhar crítico e atencioso; e às professoras Lilian Nasser e Shila Antuanett Neciosup Salas, por gentilmente traduzirem o resumo.

\section{Referências}

AGUILAR JÚNIOR, C. A.; CALDATO, J. C. Argumentação e prova matemática no PISA 2012. In: Seminário de Pesquisa em Educação Matemática do Rio de Janeiro, 4, Rio de Janeiro/RJ. Anais..., 2020, p. 1-14. Disponível em: http://eventos.sbem.com.br/index.php/spem-rj/ixspemrj/paper/viewFile/1453/1155. Acesso em: 13 dez. 2020.

AGUILAR JÚNIOR, C. A.; NASSER, L. Analisando justificativas e argumentação matemática de alunos do ensino fundamental. VIDYA, Santa Maria/RS, v. 32, n. 2, p.133-147, 2012. Disponível em: https://periodicos.ufn.edu.br/index.php/VIDYA/article/view/278/254. Acesso em: 13 dez. 2020.

ALMOULOUD, S. A. Prova e demonstração em matemática: problemática de seus processos de ensino e aprendizagem. In: Reunião Anual da ANPEd, 30, Caxambu/MG. Anais..., 2007, p. 1-18. Disponível em: https://anped.org.br/sites/default/files/gt19-2957-int.pdf. Acesso em 13 dez. 2020.

BALACHEFF, N. Preuve et démonstration en mathématiques au collège. Recherchesen Didactique des Mathématiques, Grenoble, v. 3, n. 3, p. 261-304, 1982.

Aspects of proof in pupils' practice of school mathematics. In: PIMM, D. (Ed.), Mathematics, teachers and children. Londres: Hodder and Stoughton, 1988, p. 216-235.

BOAVIDA, A. M. R. A argumentação em matemática: investigando o trabalho de duas professoras em contexto de colaboração. 996 f. Tese (Doutorado em Educação) Universidade de Lisboa, 2005. Disponível em: https://repositorio.ul.pt/bitstream/10451/3140/1/ulsd048032_td_Ana_Boavida.pdf. Acesso em: 13 dez. 2020.

BRASIL. Parâmetros curriculares nacionais: Matemática. Secretaria de Educação Fundamental. Brasília/DF: MEC / SEF, 1998. Disponível em: http://portal.mec.gov.br/seb/arquivos/pdf/matematica.pdf. Acesso em: 13 dez. 2020.

BRASIL. PCN + Ensino Médio: orientações educacionais complementares aos Parâmetros Curriculares Nacionais - Ciências da Natureza, Matemática e suas tecnologias. Secretaria de Educação Básica. Brasília/DF: MEC/SEB, 1999. Disponível em: http://portal.mec.gov.br/seb/arquivos/pdf/CienciasNatureza.pdf. Acesso em: 13 dez. 2020. 


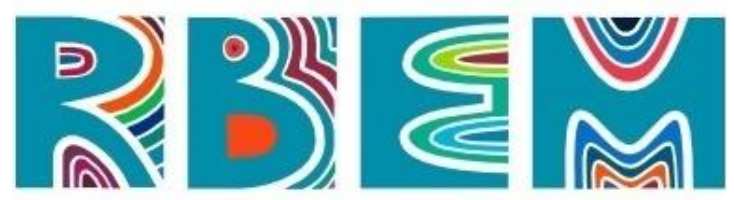

REVISTA BAIANA DE EDUCAÇÃO MATEMÁtICA

BRASIL. Instituto Nacional de Estudos e Pesquisas Educacionais Anísio Teixeira. Itens liberados - Matemática PISA 2012. Brasília/DF: 2012. Disponível em: https://download.inep.gov.br/acoes_internacionais/pisa/itens/2012/pisa_2012_matematica_ite ns_liberados.pdf Acesso em: 13 dez. 2020.

BRASIL. Instituto Nacional de Estudos e Pesquisas Educacionais Anísio Teixeira. Relatório Nacional PISA 2012: resultados brasileiros. Brasília/DF: Fundação Santillana, 2013a. Disponível em: https://download.inep.gov.br/acoes_internacionais/pisa/resultados/2014/relatorio_nacional_pi sa_2012_resultados_brasileiros.pdf. Acesso em: 13 dez. 2020.

BRASIL. Instituto Nacional de Estudos e Pesquisas Educacionais Anísio Teixeira. Matriz de avaliação de matemática - PISA 2012. Brasília/DF: 2013b. Disponível em: https://download.inep.gov.br/acoes_internacionais/pisa/marcos_referenciais/2013/matriz_aval iacao_matematica.pdf. Acesso em: 13 dez. 2020.

BRASIL. Base Nacional Comum Curricular: educação é a base. Brasília/DF: MEC/SEB, $2018 . \quad$ Disponível em: http://basenacionalcomum.mec.gov.br/images/BNCC_EI_EF_110518_versaofinal_site.pdf. Acesso em: 13 dez. 2020.

CALDATO, J. Argumentação, prova e demonstração: uma investigação sobre as concepções de ingressantes no curso de Licenciatura em Matemática. 219 f. Dissertação (Mestrado em Ensino de Matemática) - Universidade Federal do Rio de Janeiro, 2018. Disponível em: http://www.pg.im.ufrj.br/pemat/MSc\%2090_Carlos\%20Caldato\%20Correia.pdf. Acesso em: 13 dez. 2020.

CALDATO, J.; UTSUMI, M. C.; NASSER, L. Argumentação e demonstração em matemática: a visão de alunos e professores. Revista Triângulo, Uberaba/MG, v. 10 n. 2, p. 74-93, 2017.2 Disponível em: http://seer.uftm.edu.br/revistaeletronica/index.php/revistatriangulo/article/view/2583/pdf.

Acessoem: 13 dez. 2020.

DE VILLIERS, M. The role and function of proof in mathematics. Pythagoras, n. 24, p. 1724, 1990.

DE VILLIERS, M. Rethinking proof with Geometer's Sketchpad. Emeryville/CA: Key Curriculum Press, 1999.

GONSALVES, E. P. Conversas sobre iniciação à pesquisa científica. $2^{\mathrm{a}}$ ed. Campinas: Alínea, 2001.

HANNA, G. Some Pedagogical Aspects of Proof. Interchange, v. 21, n. 1, p. 6-13, 1990. 


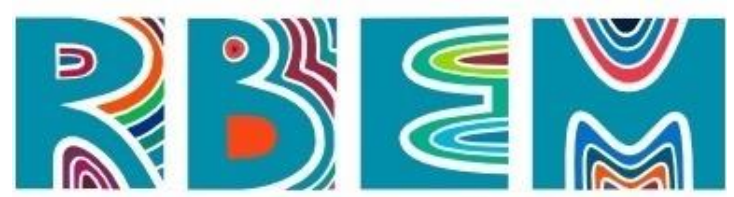

REVISTA BAIANA DE EDUCAÇÃO MATEMÁtICA

HANNA, G Challenges to the importance of proof. For the Learning Mathematics, v. 15, n. 3, p. 42-49, nov. 1995.

HEALY, L.; HOYLES, C. Justifying and proving in school mathematics: technical report on the nationwide survey. London: Institute of Education, University of London, 1998. 120 p.

JOLANDEK, E. G. Reforma curricular, avaliação em larga escala e pisa: um olhar a partir de percepções docentes. 187 f. Dissertação (Mestrado em Ensino de Ciências e Educação Matemática) - Universidade Estadual de Ponta Grossa, 2020. Disponível em: https://tede2.uepg.br/jspui/bitstream/prefix/3093/1/Emilly\%20Jolandek.pdf. Acesso em: 13 dez. 2020.

LIMA, M. L. S; SANTOS, M. C. Provas e demonstrações e níveis do pensamento geométrico: conceitos, bases epistemológicas e relações. REVEMAT, Florianópolis/SC, v. 15, n. $1,201-21, \quad 2020.20$ Disponível https://periodicos.ufsc.br/index.php/revemat/article/view/1981-1322.2020.e66702/43212.

Acesso em: 13 dez. 2020.

NOTARE, M. R.; BASSO, M. V. de A. Argumentação e Prova Matemática com Geometria Dinâmica. Novas Tecnologias na Educação, Porto Alegre/RS, v. 16, n. 1, p. 1-10, 2018. Disponível em: https://seer.ufrgs.br/renote/article/view/86021/49384. Acesso em: 13 dez. 2020.

NUNES, J. S. V; ALMOULOUD, S. A. O modelo de Toulmin e a análise da prática da argumentação em matemática. Educação Matemática Pesquisa, São Paulo/SP, v. 15, n.2, p. 487-512, 2013. Disponível em: https://revistas.pucsp.br/emp/article/viewFile/14592/pdf_1. Acesso em: 13 dez. 2020.

ORTIGÃO, M. I. R; SANTOS, M. J. C.; LIMA, R. L. Letramento em Matemática no PISA: o que sabem e podem fazer os estudantes? Zetetiké, Campinas/SP, v.26, n.2, p. 375-389, 2018. Disponível em: https://periodicos.sbu.unicamp.br/ojs/index.php/zetetike/article/view/8650093/18158.

Acessoem: 13 dez. 2020.

REID, D. A.; KNIPPING, C. Proof in Mathematics Education: Research, Learning and Teaching. Rotterdam: Sense Publishers, 2010. 251 p.

Artigo submetido em: 03/12/2020

Artigo aceito em: 22/12/2020 